\title{
A Region on Chromosome 15 Controls Intersession Habituation in Mice
}

\author{
Valerie Bolivar ${ }^{1}$ and Lorraine Flaherty ${ }^{1,2}$ \\ ${ }^{1}$ Genomics Institute, Wadsworth Center, Troy, New York 12180, and 2Department of Pediatrics, Albany Medical College, Albany, New York 12208
}

\begin{abstract}
Habituation to a novel environment, as measured by a change in exploratory activity over time, can be measured both within (intrasession) and across (intersession) sessions. The role of genetics in intrasession habituation has been investigated previously in quantitative trait loci studies, but little attention has been focused on the role of genetics on intersession habituation. We reported recently that inbred strains respond differently in an intersession habituation test. By testing a total of 25 BXD recombinant inbred lines, we were able to map a chromosomal region that strongly influences the way in which mice habituate. This region located on chromosome 15 appears to the major one affecting habituation and accounts for $80 \%$ of the genetic variance. We subsequently confirmed this map position by testing $(\mathrm{C} 57 \mathrm{BL} / 6 \mathrm{~J} \times \mathrm{DBA} / 2 \mathrm{~J}) \mathrm{F}_{2}$ mice.
\end{abstract}

Key words: habituation; recombinant inbred strain; quantitative trait loci; mice; gene; exploratory activity

\section{Introduction}

Habituation, which has been called the most ubiquitous phenomenon in animal behavior, can be found throughout the animal kingdom (Harris, 1943; Thompson and Spencer, 1966; Groves and Thompson, 1970). One form of habituation is the change in exploratory activity seen in rodents in response to continued exposure to a novel environment. That novel environment can be stimulus-rich or relatively empty. According to “cognitive map" theory (O'Keefe and Nadel, 1978), when placed in a new environment a rodent will begin to form an internal representation of the surrounding spatial information. Once this hippocampal "map" is complete, exploration of the environment will be reduced. When we observe this reduction in exploration, we say the rodent has habituated to the new environment.

Habituation can be measured both within (intrasession) and between (intersession) sessions. Whereas intrasession habituation can be classified as a measure of adaptivity, intersession habituation also reflects a memory of the environment (Muller et al., 1994). Intersession habituation appears to correlate with hippocampal mossy fiber distribution, based on a study of 25 genetically different groups of mice (combinations of BA, BALB/cJ, C57BL/6J, C57BR/cdJ and DBA/2J) (Crusio and Schwegler, 1987). Furthermore, several knock-outs/knock-downs have diminished intersession habituation response, including DAT1, Plat, and ScaI (Matilla et al., 1998; Ammassari-Teule et al., 2001; Zhuang et al., 2001).

Several studies have found intersession habituation differences between C57BL/6 and DBA/2, in either an empty open field or in one containing objects (Ammassari-Teule et al., 1995;

Received July 25, 2003; revised Aug. 28, 2003; accepted Aug. 30, 2003.

This work was supported by grants from the National Institutes of Health to L.F.

Correspondence should be addressed to Dr. Valerie Bolivar, Genomics Institute, Wadsworth Center, P.O. Box 22002, 120 New Scotland Avenue, Albany, NY 12201-2002. E-mail: bolivar@wadsworth.org.

Copyright $\odot 2003$ Society for Neuroscience $\quad$ 0270-6474/03/239435-04\$15.00/0
Ammassari-Teule and Passino, 1997; Roullet et al., 1997; Podhorna and Brown, 2002). Recently, we conducted a survey of intersession habituation behavior in eight commonly used inbred strains (Bolivar et al., 2000). Mice were placed in a darkened activity monitor for $5 \mathrm{~min}$ per day on three consecutive days. We defined habituation as a change in total distance traveled across the three testing sessions in the activity monitor. Some strains, like C57BL/6J, decreased their overall exploratory activity over the $3 \mathrm{~d}$ of testing, whereas other strains, such as A/J, increased their activity. Moreover, we altered the pattern of intersession behavior by changing the floor of the activity monitor, thus confirming that the mice were changing their activity levels based on repeated exposures to the same environment (Bolivar et al., 2000). The results of this experiment indicate that intersession habituation of activity differed among the inbred strains tested, and that these differences were further modified according to sex.

By testing a number of BXD recombinant inbred (RI) strains, a major quantitative trait locus (QTL) influencing this intersession habituation response has been mapped. This QTL resides in the proximal region of chromosome 15.

\section{Materials and Methods}

Animals. Experimentally naive male mice from 25 BXD RI lines (19-26 mice were tested per line) were used for these experiments. In addition, $32 \mathrm{C} 57 \mathrm{BL} / 6 \mathrm{~J}$ (B6) and $32 \mathrm{DBA} / 2 \mathrm{~J}$ (D2) male mice were tested. B6, D2, and all RI lines were obtained from The Jackson Laboratory (Bar Harbor, $\mathrm{ME}$ ) and were maintained in our colony at the Wadsworth Center for 2-3 weeks before the onset of behavioral testing. In addition, $(\mathrm{B} 6 \times \mathrm{D} 2) \mathrm{F}_{1}$ (B6D2F1) breeding pairs were purchased from The Jackson Laboratory and bred in our facility to produce $(\mathrm{B} 6 \times \mathrm{D} 2) \mathrm{F}_{2}(\mathrm{~B} 6 \mathrm{D} 2 \mathrm{~F} 2)$ mice. A total of $72(\mathrm{~B} 6 \times \mathrm{D} 2) \mathrm{F}_{2}(\mathrm{~B} 6 \mathrm{D} 2 \mathrm{~F} 2)$ males were tested for habituation. Mice were housed in clear Plexiglas cages $(29 \times 18 \times 12.5 \mathrm{~cm})$ with stainless steel wire lids and filter tops, in a temperature-controlled $\left(68-72^{\circ} \mathrm{F}\right)$ room; they were maintained on a $12 \mathrm{hr}$ light/dark cycle (lights on at 7:00 A.M.). Mice were tested during the light phase of the light/dark cycle.

Exploratory behavior procedure. Exploratory behaviors were measured with Digiscan 16-beam automated activity monitors $(42 \times 42 \times 30 \mathrm{~cm}$; 

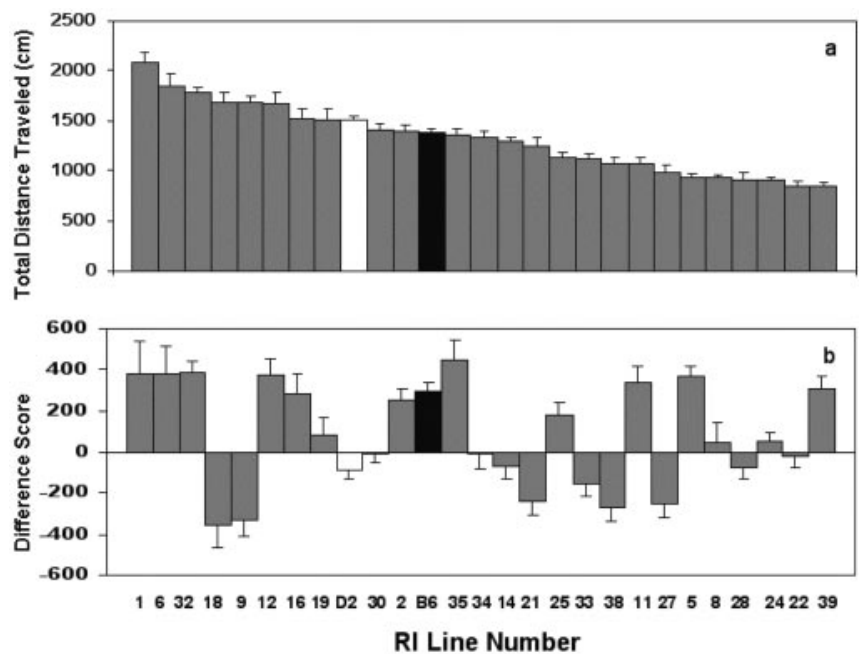

Figure 1. Performance differences of RI lines in the activity monitor. $a$, Mean ( \pm SEM) total distance traveled on day 1.b. Mean ( \pm SEM) habituation score (day 1 total distance - day 3 total distance). B6 (black column) and D2 (white column) groups are included for comparison purposes.

AccuScan Instruments, Columbus, $\mathrm{OH})$. The activity monitors were enclosed in melamine sound-attenuating chambers $(65 \times 55 \times 55 \mathrm{~cm}$; Med Associates, St. Albans, VT). The testing procedure has been described in detail previously (Bolivar et al., 2000). Briefly, each mouse was weighed, put in a holding cage for $5 \mathrm{~min}$, and then placed in the center of a dark activity monitor for a 5-min testing period. Mice were tested once per day on three consecutive days. The total distance traveled was measured each day by the Digiscan system, and the data were analyzed by one-way ANOVA. The habituation score (difference score) was defined as day 1 total distance traveled minus day 3 total distance traveled. The resulting habituation score data were analyzed by one-way ANOVA. The Map Manager program QTXb17 (http://mapmgr.roswellpark.org/mapmgr. html) was used to determine the location of the chromosomal regions influencing these traits, as well as calculating the genetic variance. The strength of association between genotype and phenotype was calculated by a pointbiserial correlation. The B6 and D2 data were analyzed by $t$ test. For the $(\mathrm{B} 6 \times \mathrm{D} 2) \mathrm{F}_{2}$ data, habituation scores for the three possible genotypes "bb," "bd," and "dd" were analyzed by one-way ANOVA. The Fisher's PLSD post hoc test was used to further examine differences.

\section{Results}

RI lines showed differences in their first-day exploratory behavior in the activity monitor $\left(F_{(24,478)}=22.05, p<0.0001\right)$ (Fig. 1a). The mean distance traveled ranged from 840.95 to $2083.40 \mathrm{~cm}$. For comparison purposes, B6 and D2 are also included (Fig. 1a). D2 males were significantly more active than were B6 males $\left(t_{(62)}\right.$ $=-2.11, p=0.0386$ ) (Fig. 1a).

There were significant differences in habituation scores, as measured by day 1 distance traveled minus day 3 distance traveled, among the RI lines $\left(F_{(24,478)}=9.94, p<0.0001\right)($ Fig. $1 b)$. Some of the RI lines tested behaved like B6, showing a reduction in activity from day 1 to day 3 (positive habituation score). Others showed an increase in activity from day 1 to day 3 and more resembled D2 (negative habituation score). Others were intermediate in their behavioral scores (Fig. 1b). The RI line means showed no significant correlation $(r=0.223, p=0.287)$ between total distance traveled on day 1 and the habituation score (Fig. 1, compare $a, b)$.

The Map Manager program was used to calculate linkage relationships for both traits. Although no significant linkage relationship was found for total distance traveled on day 1, a very significant linkage was found for the habituation score (Fig. 2). A

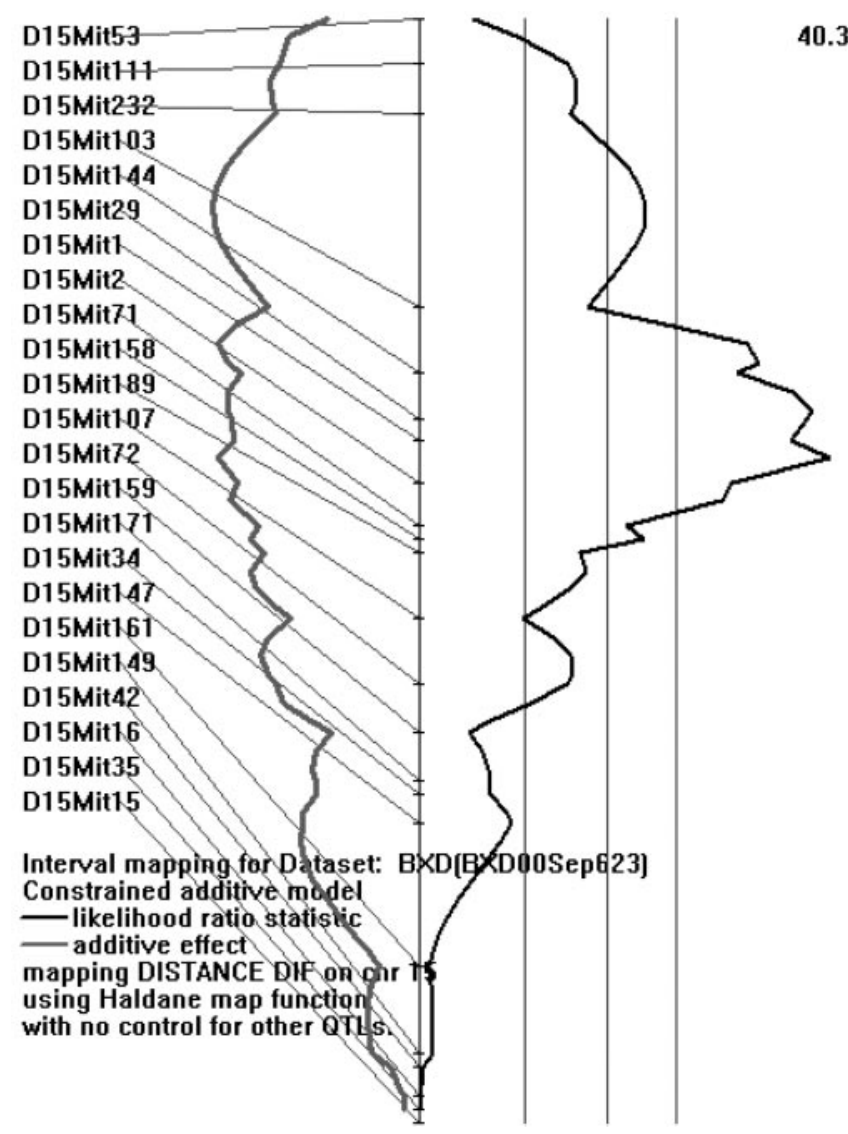

Figure 2. Map Manager output of chromosome 15 showing QTL peak. The LRS for this QTL was 40.3 .

peak likelihood ratio statistic (LRS) score of 40.3 was obtained for a proximal region of chromosome 15. This LRS value corresponds to a logarithm of the odds (LOD) score of 8.8 and is highly significant (Lander and Kruglyak, 1995). No other region reached a LOD score above 3.0. This region of chromosome 15 accounts for $80 \%$ of the genetic variance (calculated by Map Manager). Habituation scores were highly associated with genotype (point-biserial correlation coefficient $=0.845, p<0.0001$ ). Thus, it appears that there is one major region controlling habituation, and that it is located on the proximal region of chromosome 15.

To confirm this observation and linkage relationship, we performed a small B6D2F2 intercross and typed 72 mice for chromosome 15 genetic markers. As can be seen in Table 1, there was a strong relationship between the genotype at D15Mit144 and the habituation scores $\left(F_{(2,69)}=4.55, p=0.014\right)$. The highest habituation scores belonged to those mice genotyping bb and the lowest scores to those typing dd at that marker. There was a statistically significant difference between bb and dd $(p=0.0036)$. The bd genotype group was significantly different from bb $(p=$ $0.0359)$, but not from dd. Thus, the results of our intercross confirmed the RI line results.

\section{Discussion}

A single QTL on chromosome 15 (between 32 and $46 \mathrm{cM}$ ) was identified in our BXD RI line study, accounting for $80 \%$ of the genetic variance. In the mapping of this QTL, the use of RI lines was shown to be a highly effective strategy. Even though there was variation among animals of the same genotype, the use of the RI 
Table 1. Genotypes and habituation scores of B6D2F2 intercross

\begin{tabular}{|c|c|c|c|c|c|}
\hline Marker & cM position & $\mathrm{bb}$ & $\mathrm{bd}$ & $\mathrm{dd}$ & $p$ value (dd vs bb) \\
\hline D15MIT66 & 32.2 & $77.8 \pm 64.3$ & $-68.4 \pm 42.1$ & $-176.8 \pm 31.2$ & 0.0104 \\
\hline D15MIT144 & 32.2 & $107.2 \pm 65.2$ & $-68.4 \pm 42.1$ & $-176.8 \pm 31.2$ & 0.0036 \\
\hline D15MIT92 & 35.3 & $72.9 \pm 60.6$ & $-66.2 \pm 44.0$ & $-176.8 \pm 31.2$ & 0.0074 \\
\hline D15MIT90 & 36.0 & $79.8 \pm 65.5$ & $-64.9 \pm 43.0$ & $-176.8 \pm 31.2$ & 0.0072 \\
\hline D15MIT156 & 39.1 & $51.4 \pm 60.1$ & $-62.2 \pm 44.9$ & $-176.8 \pm 31.2$ & 0.0128 \\
\hline
\end{tabular}

$\mathrm{b}, \mathrm{B} 6 ; \mathrm{d}, \mathrm{D} 2$. Habituation score $=$ distance traveled day 1 minus distance traveled day $3 . n=72$.

lines reduced these background effects, making it possible to map this genetic locus with precision. However, because there is potential for false-positive QTLs with any RI line analysis (Belknap et al., 1996), we confirmed the observation with a small B6D2F2 population.

As is evident from the habituation scores, the change in activity between day 1 and day 3 varied among the RI lines tested. Some lines behaved like B6, displaying a decrease in activity from day 1 to day 3; some behaved like D2, displaying an increase in activity; and other lines did not display any change in total distance traveled (Fig. 1). For this study we have defined habituation to be "any change in activity, either an increase or a decrease." Therefore, both B6 and D2 habituate to the activity monitor, although the direction of the activity change differs. This is slightly unlike the classical definition of habituation, which generally accounts only for a decrease in activity.

Our definition more closely aligns with that of Crusio and Schwegler (1987). In their study of the relationship between hippocampal mossy fiber distribution and open-field intersession habituation, they defined habituation as any change in activity from day 1 to day 2. They reported significant decreases (day 1 to day 2) in some exploratory activity variables, such as locomotor activity, sniffing, and gnawing. Other variables, such as rearing, jumping, and grooming showed an increase from day 1 to day 2. Crusio and Schwegler suggest that behaviors such as rearing and jumping display increases over time, as the environment becomes less novel to the animal. They also suggest that in a novel environment these types of exploratory behaviors would make the mouse more vulnerable to predators; thus, only after the animal becomes familiar with the environment should jumping and rearing increase. Nevertheless, there is evidence of habituation to the testing environment for both categories of variables. Thus, it can be argued that changes in behavior (habituation) can occur in either direction (increase or decrease over time), and that only individuals not displaying any change in behavior can be classified as nonhabituators.

As measured in our study, intersession habituation cannot simply be equated with intrasession habituation of exploratory activity. As Muller and colleagues (1994) suggest, if intrasession habituation reflects adaptivity and intersession habituation reflects both adaptivity and memory of the environment, we would expect differences in the pathways involved in the two processes. Therefore, it is not surprising that our QTL does not overlap with the QTLs obtained previously for intrasession habituation (Radcliffe et al., 1998; Koyner et al., 2000). The two forms of habituation are probably not the same, and we should not expect the same neural pathways or genes to be involved.

Intersession habituation should also not be equated with baseline activity levels. In our study, there was no significant correlation between total distance traveled on day 1 and the habituation score. The lack of a direct association between baseline activity and habituation score is also evident in our QTL findings. No significant linkage was found for total distance on day 1 , in con- trast with the highly significant QTL that we obtained for habituation scores. This is additional evidence that these variables are measuring different phenotypes that are under separate genetic controls. Our inability to find a QTL for day 1 exploratory activity is not surprising, because RI line analyses are notorious for their low power, caused by the low numbers of available lines (Belknap et al., 1996). However, one previous RI line study has identified several QTLs for activity during the first $5 \mathrm{~min}$ in the activity monitor (Koyner et al., 2000). It is unclear why we were unable to replicate these findings. Different activity monitor lighting conditions between the two studies may be responsible. In light of the lack of significant QTLs for baseline activity, our highly significant QTL on chromosome 15 for habituation appears more dramatic and suggestive of some other powerful underlying process.

A number of neurobiological QTLs also map to this region of chromosome 15 (http://www.webqtl.org). These include dopamine receptor D1 expression in the caudate putamen; dopamine receptor D2 expression in the caudate putamen, nucleus accumbens, and ventral midbrain; and dopamine transporter expression in the caudate putamen and frontal cortex (Jones et al., 1999). However, it is uncertain whether these mapping relationships have any functional significance.

A number of possible processes may influence habituation behavior, including spatial memory of the environment, changes in anxiety level, and responsiveness to experimentation. It is interesting that our QTL is in a region of chromosome 15 similar to those reported previously for a number of behaviors, including open-field locomotor activity, mirror chamber behavior, elevated plus maze performance, light/dark box behavior, square maze performance, and responsiveness to drugs such as ethanol and cocaine (Phillips et al., 1994; Cunningham, 1995; Flint et al., 1995; Rodriguez et al., 1995; Gershenfeld and Paul, 1997; Gershenfeld et al., 1997; Phillips et al., 1998; Jones et al., 1999; Boyle and Gill, 2001; Turri et al., 2001a,b; Downing et al., 2003). Turri and colleagues (2001b) suggest that chromosome 15 may be related to avoidance behavior rather than ambulation. Taken together, the QTLs from these studies and our own may indicate that this region of chromosome 15 is more related to "anxiety" than to either activity or memory. Obviously, identification of the gene or genes responsible will shed light on the pathways involved in habituation and will provide evidence of the possible anxiety component of this behavior.

\section{References}

Ammassari-Teule M, Passino E (1997) The dorsal hippocampus is selectively involved in the processing of spatial information even in mice with a genetic hippocampal dysfunction. Psychobiology 25:118-125.

Ammassari-Teule M, Tozzi A, Rossi-Arnaud C, Save E, Thinus-Blanc C (1995) Reactions to spatial and nonspatial change in two inbred strains of mice: further evidence supporting the hippocampal dysfunction hypothesis in the DBA/2 strain. Psychobiology 23:284-289.

Ammassari-Teule M, Restivo L, Pietteur V, Passino E (2001) Learning about the context in genetically-defined mice. Behav Brain Res 125:195-204. 
Belknap JK, Mitchell SR, O’Toole LA, Helms ML, Crabbe JC (1996) Type I and type II error rates for quantitative trait loci (QTL) mapping studies using recombinant inbred mouse strains. Behav Genet 26:149-160.

Bolivar VJ, Caldarone BJ, Reilly AA, Flaherty L (2000) Habituation of activity in an open field: a survey of inbred strains and F1 hybrids. Behav Genet 30:285-293.

Boyle AEL, Gill K (2001) Sensitivity of AXB/BXA recombinant inbred lines of mice to the locomotor activating effects of cocaine: a quantitative trait loci analysis. Pharmacogenetics 11:255-264.

Crusio WE, Schwegler H (1987) Hippocampal mossy fiber distribution covaries with open-field habituation in the mouse. Behav Brain Res 26:153-158.

Cunningham CL (1995) Localization of genes influencing ethanol-induced conditioned place preference and locomotor activity in BXD recombinant inbred mice. Psychopharmacology 120:28-41.

Downing C, Rodd-Henricks KK, Flaherty L, Dudek BC (2003) Genetic analysis of the psychomotor stimulant effect of ethanol. Genes Brain Behav 2:140-151.

Flint J, Corley R, DeFries JC, Fulker DW, Gray JA, Miller S, Collins AC (1995) A simple genetic basis for a complex psychological trait in laboratory mice. Science 269:1432-1435.

Gershenfeld HK, Paul SM (1997) Mapping quantitative trait loci for fearlike behaviors in mice. Genomics 46:1-8.

Gershenfeld HK, Neumann PE, Mathis C, Crawley JN, Li X, Paul SM (1997) Mapping quantitative trait loci for open-field behavior in mice. Behav Genet 27:201-210.

Groves PM, Thompson RF (1970) Habituation: a dual-process theory. Psychol Rev 77:419-450.

Harris JD (1943) Habituatory response decrement in the intact organism. Psychol Bull 40:385-422.

Jones BC, Tarantino LM, Rodriguez LA, Reed CL, McClearn GE, Plomin R, Erwin VG (1999) Quantitative-trait loci analysis of cocaine-related behaviours and neurochemistry. Pharmacogenetics 9:607-617.

Koyner J, Demarest K, McCaughran J, Cipp L, Hitzemann R (2000) Identification and time dependence of quantitative trait loci for basal locomotor activity in the BXD recombinant inbred series and a B6D2F2 intercross. Behav Genet 30:159-170.

Lander E, Kruglyak L (1995) Genetic dissection of complex traits: guidelines for interpreting and reporting linkage results. Nat Genet 11:241-247.

Matilla A, Roberson ED, Banfi S, Morales J, Armstrong DL, Burright EN, Orr
HT, Sweatt JD, Zoghbi HY, Matzuk MM (1998) Mice lacking ataxin-1 display learning deficits and decreased hippocampal paired-pulse facilitation. J Neurosci 18:5508-5516.

Muller U, Cristina N, Li ZW, Wolfer DP, Lipp HP, Rulicke T, Brandner S, Aguzzi A, Weissmann C (1994) Behavioral and anatomical deficits in mice homozygous for a modified beta-amyloid precursor protein gene. Cell 79:755-765.

O’Keefe J, Nadel L (1978) The hippocampus as a cognitive map. Oxford: Clarendon Press.

Phillips TJ, Crabbe JC, Metten P, Belknap JK (1994) Localization of genes affecting alcohol drinking in mice. Alcohol Clin Exp Res 18:931-941.

Phillips TJ, Huson MG, McKinnon CS (1998) Localization of genes mediating acute and sensitized locomotor responses to cocaine in BXD/Ty recombinant inbred mice. J Neurosci 18:3023-3034.

Podhorna J, Brown RE (2002) Strain differences in activity and emotionality do not account for differences in learning and memory performance between C57BL/6 and DBA/2 mice. Genes Brain Behav 1:96-110.

Radcliffe RA, Jones BC, Erwin VG (1998) Mapping of provisional quantitative trait loci influencing temporal variation in locomotor activity in the LS $\times$ SS recombinant inbred strains. Behav Genet 28:39-47.

Rodriguez LA, Plomin R, Blizard DA, Jones BC, McClearn GE (1995) Alcohol acceptance, preference, and sensitivity in mice. II. Quantitative trait loci mapping analysis using BXD recombinant inbred strains. Alcohol Clin Exp Res 19:367-373.

Roullet P, Mele A, Ammassari-Teule M (1997) Ibotenic lesions of the nucleus accumbens promote reactivity to spatial novelty in nonreactive DBA mice: implications for neural mechanisms subserving spatial information encoding. Behav Neurosci 111:976-984.

Thompson RF, Spencer WA (1966) Habituation: a model phenomenon for the study of neuronal substrates of behavior. Psychol Rev 73:16-43.

Turri MG, Henderson ND, DeFries JC, Flint J (2001a) Quantitative trait locus mapping in laboratory mice derived from a replicated selection experiment for open-field activity. Genetics 158:1217-1226.

Turri MG, Datta SR, DeFries J, Henderson ND, Flint J (2001b) QTL analysis identifies multiple behavioral dimensions in ethological tests of anxiety in laboratory mice. Curr Biol 11:725-734.

Zhuang X, Oosting RS, Jones SR, Gainetdinov RR, Miller GW, Caron MG, Hen R (2001) Hyperactivity and impaired response habituation in hyperdopaminergic mice. Proc Natl Acad Sci USA 98:1982-1987. 